\title{
Bancos de leche humana y COVID-19: revisión de alcance sistemático
}

\author{
Milk banks and COVID-19: Scoping review \\ Bancos de leite e COVID-19: revisão de alcance sistemático
}

\begin{abstract}
Álvaro Jácome-Orozco*1, Fabio Sierra-Matamoros², Rossana López-Sáleme³ ${ }^{3}$ Carmen Díaz-López ${ }^{3}$, Nubia Castiblanco-Lopez ${ }^{4}$, Isabel Rodriguez-Hernandez ${ }^{5}$, Doris Amparo Parada-Rico ${ }^{3}$
\end{abstract}

Recibido: 23 de julio de 2020. Aceptado para publicación: 10 de septiembre de 2020

Publicado primero en línea: 24 de septiembre de 2020

https://doi.org/10.35454/rncm.v4n1.182

\section{Resumen}

Objetivo: revisar la información publicada sobre el manejo de la bioseguridad en los bancos de leche humana, el procesamiento de muestras de leche humana y la selección de donantes durante la pandemia por COVID-19.

Métodos: se realizó una búsqueda bibliográfica en Medline, EMBASE, LILACS, bases de datos de la Organización Mundial de la Salud, Base de Datos Cochrane de Revisiones Sistemáticas y Google Scholar. Se incluyeron estudios con una metodología cualitativa y cuantitativa como revisiones sistemáticas, estudios observacionales, informes de casos, así como documentos de gestión técnica, editoriales con propuestas de gestión técnica, en inglés y español, publicados entre el 1 de enero y el 2 de junio de 2020. Los términos MeSH utilizados fueron: bancos de leche, lactancia materna, virus SARS-COV-2 y COVID-19. Los términos de DeCS fueron: bancos de leche, extracción de leche, virus del SARS e infecciones por coronavirus.

Resultados: se encontraron 577 títulos, se excluyeron 537 en la selección y 18 en la fase de revisión de texto completo, fueron incluidos 22 títulos para síntesis. No se encontró evidencia de transmisión viral a través de la leche humana, pero sí de transmisión por contacto. Se encontraron medidas de barrera para prevenir el contagio. Existen diferentes posiciones sobre el uso de leche humana pasteurizada o no pasteurizada, debido a las propiedades

\section{Summary}

Objective: To conduct a review of the scope of published information on biosecurity in human milk banks during the COVID-19 pandemic.

Methodology: A bibliographic search was carried out in the Medline, EMBASE, LILACS, and World Health Organization databases, the Cochrane Database of Systematic Reviews, and Google Scholar, of studies with qualitative and quantitative methodology such as systematic reviews, observational studies, case reports, as well as technical management documents and editorials with technical management proposals, published both in English and Spanish between January 1 and June 2, 2020.

The MeSH terms used were: milk banks, breastfeeding, SARS virus, and COVID-19. The DeCS terms were: milk banks, milk extraction, SARS virus, and coronavirus infections.

Results: Overall, 577 titles were found, 537 were excluded in the selection and 18 in the full-text review phase; 22 were included in the synthesis. No evidence of viral transmission was found for human milk, but evidence regarding contact transmission as well as barrier measures to prevent contagion was identified. There are different positions on the use of pasteurized or unpasteurized human milk, due to the protective biological properties that breast milk provides without the pasteurization process, and the lack of evidence of COVID-19 transmission in milk.

\section{Resumo}

Objetivo: rever as informações publicadas sobre a gestão da biossegurança nos bancos de leite humano, o processamento de amostras de leite humano e a seleção de doadores durante a pandemia por COVID-19.

Métodos: foi realizada uma pesquisa bibliográfica nas bases de dados Medline, EMBASE, LILACS, bases de dados da Organização Mundial de Saúde, Cochrane Database of Systematic Reviews e Google Scholar. Foram incluídos estudos com uma metodologia qualitativa e quantitativa, como revisões sistemáticas, estudos observacionais, relatos de casos, bem como documentos de gestão técnica, editoriais com propostas de gestão técnica, em inglês e espanhol, publicados entre 1 de janeiro e 2 de junho de 2020 . Os termos MeSH usados foram: bancos de leite, extração de leite, vírus SARS-COV2 e COVID-19. Os termos do DeCS foram: bancos de leite, aleitamento materno, vírus SARS e infeções por coronavírus.

Resultados: foram encontrados 577 títulos, se excluíram 537 na seleção e 18 na fase de revisão do texto completo, foram incluídos 22 títulos para síntese. Não se encontrou evidência de transmissão viral através do leite humano, mas sim de transmissão por contato. Foram encontradas medidas de barreira para prevenir o contágio. Existem diferentes posições quanto ao uso do leite humano pasteurizado ou não pasteurizado, devido às 
biológicas protectoras que proporciona la leche materna no pasteurizada. Como medidas principales de protección contra la infección se hace énfasis en el uso de leche materna autóloga y en garantizar el buen estado de salud de la mujer donante.

Conclusión: las medidas de bioseguridad recomendadas en bancos de leche humana, previa valoración del estado de salud de la mujer donante, determina el uso de leche humana heteróloga u homóloga. Se recomienda fomentar el uso de leche autóloga no pasteurizada.

Palabras clave: leche materna, bancos de leche, virus del SARS, infecciones por coronavirus.
Conclusion: In terms of biosecurity measures, it is essential to assess the health of the donor, encourage the use of standardized unpasteurized milk as well as the use of pasteurized heterologous human milk depending on the relevant circumstances, and to implement protective measures in human milk banks.

Keywords: Breast milk extraction; Milk banks; SARS; SARS virus; Coronavirus infections. propriedades biológicas protetoras que o leite humano não pasteurizado proporciona. As principais medidas de proteção contra a infeção se faz enfase no uso de leite materno autólogo (LH) e a garantia da boa saúde da mulher doadora.

Conclusão: as medidas de biossegurança recomendadas em bancos de leite humano, avaliação prévia do estado de saúde da doadora, determinar o uso de leite humano heterólogo ou homólogo. Recomenda-se fomentar o uso de leite autólogo não pasteurizado.

Palavras-chave: leite materno, bancos de leite, vírus SARS, infeções por coronavírus.
Departamento de Pediatría. Clínica Country. RED INLAMA Bogotá, D.C.,
Colombia.
Fundación Universitaria de Ciencias de la Salud - FUCS. Bogotá, D.C.,
Colombia.

*Correspondencia: Álvaro Jácome-Orozco alvarjacome@gmail.com

\section{INTRODUCCIÓN}

El 31 de diciembre de 2019 el Centro Chino para el Control y la Prevención de Enfermedades recibió información del primer caso de lo que ahora se conoce como la Coronavirus Disease - 19 (COVID-19, por su sigla en inglés) por coronavirus 2 (SARS-CoV-2) ${ }^{(1)}$. Tres días más tarde, el 3 de enero de 2020, China informó 44 nuevos casos, cuatro días después las autoridades sanitarias de ese país habían aislado un nuevo coronavirus y el 12 de enero compartían con el mundo su secuencia genética ${ }^{(2,3)}$.

Poco tiempo después, el 11 de febrero, el Comité Internacional de Taxonomía de Virus (ICTV) daba el nombre de "Síndrome Respiratorio Agudo Severo por coronavirus 2 (SARS-CoV-2)» a este nuevo virus ${ }^{(4)}$. Este nombre fue escogido porque, aunque este virus está relacionado genéticamente, es diferente a coronavirus previos responsables del Síndrome Respiratorio Agudo Severo (SRAS) de $2003^{(5)}$. La Organización Mundial de la Salud (OMS) acortó el nombre de la enfermedad por SARS-CoV-2 a "COVID-19"(6).

Los coronavirus, llamados así por los picos en forma de corona en su superficie (en latín: coronam), son virus RNA que pertenecen a la subfamilia Coronvirinae de la

\footnotetext{
3 Universidad de Cartagena, RED INLAMA, Cartagena, D.T., Colombia.

4 Universidad Nacional, RED INLAMA, Bogotá, D.C., Colombia.

5 Fundación Universitaria Sanitas, RED INLAMA, Bogotá, D.C., Colombia.
}

familia Coronaviridae del orden Nidovirales ${ }^{(7)}$. Tienen cuatro subgrupos principales: alfa, beta, gamma y delta, según su estructura genómica. Los alfa y beta coronavirus infectan solo a los mamíferos, y generalmente causan síntomas respiratorios en humanos y gastroenteritis en otros animales ${ }^{(8) .}$

La experiencia en China frente a la enfermedad, puso de manifiesto grupos de población con respuestas diferentes a la infección por SARS-CoV-2 ${ }^{(9)}$ tales como ancianos, personas con comorbilidades e inmunosuprimidos $^{(10,11)}$. Otros grupos poblacionales con manejo clínico específico frente al riesgo de infección por este virus son las mujeres embarazadas, en atención posparto y recién nacidos ${ }^{(10)}$.

Con la declaración de estado de pandemia por la WHO el 11 de marzo de $2020^{(12)}$ la actividad en la atención materno infantil, específicamente la atención del parto, recién nacidos y manejo de la lactancia materna, requirió revisar los procesos de atención en estos grupos poblacionales ${ }^{(1,13,14)}$. De igual manera, el manejo de bancos de leche y el uso de leche humana donada con destino a la población de recién nacidos prematuros, planteó problemas específicos teniendo en cuenta el impacto social y en salud que tiene este tema y el riesgo de infección ${ }^{(15)}$. 
Los bancos de leche humana (BLH) son definidos como un servicio especializado, responsable de la promoción, protección y apoyo a la lactancia materna, que realiza actividades de recolección de leche humana de donantes (LHD), proceso, control de calidad, clasificación, conservación y distribución de la misma ${ }^{(16)}$. La actividad de extracción y conservación de la leche, hace referencia a la forma como los BLH realizan la extracción y manejo de las alícuotas, y aplican los procesos de bioseguridad y reglamentan su transporte ${ }^{(17)}$. La pasteurización está definida como el proceso mecánico de tratamiento de la leche orientada a la destrucción de material biológico infeccioso y los procesos que se requieren para asegurar la calidad del producto a su destino final ${ }^{(17,18)}$.

El contexto de esta revisión es el material publicado sobre los bancos de leche humana (BLH) en países que experimentaron la pandemia por SARS-CoV-2/ COVID-19, basados en sus experiencias, el manejo de normas de bioseguridad para la selección de donantes, transporte, almacenamiento, extracción, conservación, re-envase y pasteurización de leche humana ${ }^{(17,19,20)}$.

Se plantea realizar una revisión de alcance ${ }^{(21,22)}$ de la literatura médica disponible sobre el tema con objeto de evaluar 1) la información emergente relacionada con bioseguridad en $\mathrm{BLH}, 2$ ) el procesamiento de muestras de $\mathrm{LH}_{\text {y }} 3$ ) la selección de donantes ${ }^{(22)}$.

\section{MÉTODO}

\section{Diseño}

Es una revisión sistemática de alcance basada en la metodología del Instituto Joanna Briggs ${ }^{(22)}$.

\section{Tipo de fuentes consultadas}

Se incluyó información relacionada con el manejo de bancos de leche humana y la actual pandemia de SARSCoV-2/COVID-19; los temas seleccionados para la presente revisión de alcance sobre el tema de BLH e infección por virus SARS-CoV-2/COVID-19 fueron:

- Experiencias del manejo de los BLH en las condiciones de pandemia causada por SARS-CoV-2/ COVID-19.

- Estudios técnicos sobre procesos de pasteurización en bancos de leche durante la pandemia por SARSCoV-2/COVID-19.

- Propuestas de manejo de bancos de leche humana en el marco de la pandemia por SARS-CoV-2/ COVID-19.
- Normas de bioseguridad para donantes y manejo clínico de selección.

- Riesgo de transmisión viral del SARS-CoV-2/ COVID-19 a través de la leche ${ }^{(23,24)}$.

\section{Criterios de inclusión}

- Estudios con metodología cualitativa y cuantitativa: revisiones sistemáticas, estudios observacionales, reportes de casos, documentos de manejo técnico, editoriales con propuestas de manejo técnico de muestras para BLH.

- Como límites de búsqueda se incluyó el idioma (documentos escritos en inglés y en español).

- El tiempo de publicación (publicados entre el 1 de enero al 2 de junio de 2020).

- Documentos técnicos con otras fechas de publicación para definir algunos de los conceptos y procesos.

\section{Criterios de exclusión}

- Se excluyeron todos los artículos que aunque abordaban el tema de bancos de leche humana no se relacionaban con la actual pandemia.

\section{Estrategia de búsqueda}

Se realizaron búsquedas en las siguientes bases de datos: Medline (por medio de Pubmed), EMBASE, LILACS, bases de datos de la Organización Mundial de la Salud (OMS), Cochrane Database of Systematics Reviews y Google Scholar).

Se utilizaron los siguientes términos de búsqueda en inglés: human milk bank, human milk donor, Severe Acute Respiratory Syndrome (SARS), el concepto suplementario COVID-19, y los siguientes en español: bancos de leche humana, donante de leche humana, Síndrome Respiratorio Agudo Severo (SARS) infecciones por coronavirus y COVID-19. En la Tabla 1 se presentan los términos de búsqueda empleados en cada una de las bases de datos.

Es importante anotar que varios de los artículos revisados no han sido publicados aún (literatura gris) por lo que se emplearon bases de artículos en pre publicación como son BioRxiv y MedRxiv.

\section{Tamización de referencias y selección de estudios}

La selección de información se hizo en dos fases, la primera por título y resumen, la segunda fase por texto 
Tabla 1. Estrategias de búsqueda empleadas

\begin{tabular}{|c|c|}
\hline $\begin{array}{c}\text { Base de } \\
\text { datos }\end{array}$ & Estrategia de búsqueda \\
\hline $\begin{array}{l}\text { Medline (vía } \\
\text { pubmed) }\end{array}$ & $\begin{array}{l}\text { (milk banks[MeSH Terms] OR breast feeding[MeSH } \\
\text { Terms]) AND (SARS virus[MeSH Terms] OR COVID19 } \\
\text { virus) }\end{array}$ \\
\hline Emb & $\begin{array}{l}\text { \#1. ('milk bank'/exp OR 'breast feeding'/exp) AND } \\
\text { ('sars coronavirus'/exp OR 'coronavirus disease } \\
\text { 2019'/exp) } \\
\text { \#2. \#1 AND 2020:py AND [embase]/lim NOT } \\
\text { ([embase]/lim AND [medline]/lim) }\end{array}$ \\
\hline $\begin{array}{l}\text { Cochrane } \\
\text { Database of } \\
\text { Systematic } \\
\text { reviews }\end{array}$ & $\begin{array}{l}\text { \#1. MeSH descriptor: [Milk Banks] this term only } \\
\text { \#2. MeSH descriptor: [Breast Feeding] explode all } \\
\text { trees } \\
\text { \#3. MeSH descriptor: [SARS Virus] explode all trees } \\
\text { \#4. milk banks } \\
\text { \#5. breast feeding } \\
\text { \#6. sars virus } \\
\text { \#7. (\#1 OR \#2 OR\#4 OR \#5) AND (\#3 OR \#6) }\end{array}$ \\
\hline $\begin{array}{l}\text { Scholar } \\
\text { Google }\end{array}$ & $\begin{array}{l}\text { ("human milk bank" OR "human milk donor") AND } \\
\text { ("Severe Acute Respiratory Syndrome" OR "SARS" } \\
\text { OR "COVID 19") }\end{array}$ \\
\hline Lilacs & $\begin{array}{l}\text { tw:((tw:(("human milk bank" OR "breast feeding"))) } \\
\text { AND (tw:(("Severe Acute Respiratory Syndrome" } \\
\text { OR "SARS" OR "COVID 19")))) AND (db:("LILACS")) }\end{array}$ \\
\hline
\end{tabular}

completo. Todo el proceso se hizo en duplicado y de forma independiente. En los casos de desacuerdo, se resolvió mediante discusión de criterios de inclusión.

\section{Evaluación de la calidad de los estudios}

En los casos en los que aplicó, se utilizó la metodología propuesta por el Instituto Joanna Briggs para la evaluación de estudios cualitativos y cuantitativos observacionales ${ }^{(22)}$.

\section{Extracción de datos}

La selección de los documentos y desarrollo de resúmenes, fue realizada por un investigador, la verificación de los datos con las fuentes originales fue realizada por un segundo investigador evaluando aleatoriamente $10 \%$ de la bibliografía. Cuatro coinvestigadores conformaron el equipo de búsqueda de información inicial.

Se empleó formulario prediseñado en Excel ${ }^{\varpi}$ para referenciar la siguiente información: base de datos bibliográfica, año de publicación, nombre de la revista, diseño, autores, país e idioma, preguntas de estudio, objetivos, intervenciones, tipo de intervención y comparador, un breve resumen sobre los resultados o contenido de la publicación.

Se elaboró un diagrama de flujo PRISMA ${ }^{(25)}$ dando cuenta de los resultados de las búsquedas y del proceso de tamización y selección por texto completo, como se observa en la Figura 1.

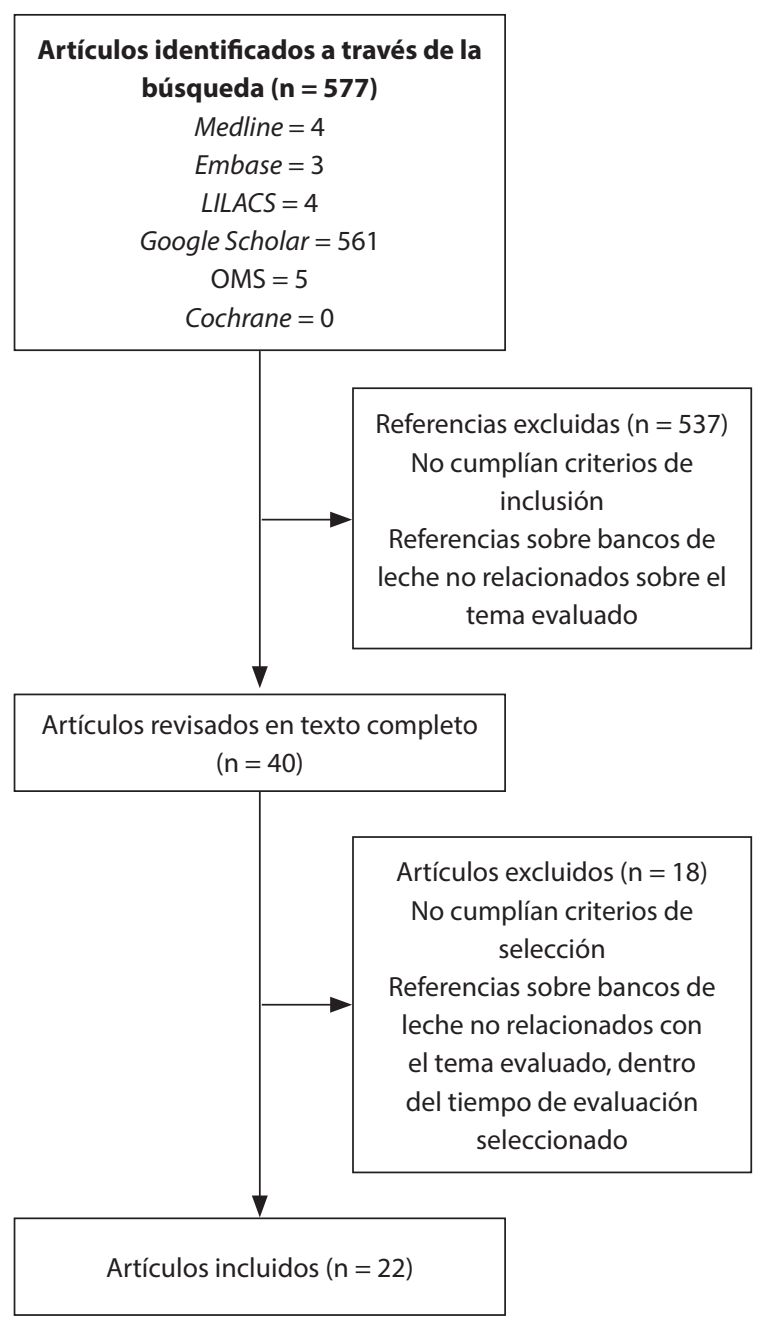

Figura 1. Diagrama PRISMA del proceso de búsqueda, tamización y selección.

\section{Análisis y presentación de resultados}

Para determinar las categorías de presentación de los resultados se revisaron las orientaciones técnicas de los BLH publicados por el Ministerio de Salud para Colombia $^{(17)}$; así, la información fue presentada acorde con las siguientes categorías:

- Procesos de captación, selección y acompañamiento de donantes 
- Extracción y conservación de la leche y manejo de alícuotas y envases

- Transporte de la leche en los BLH

- Transmisión vertical

- Pasteurización

- Evidencia bacteriológica en los procesos de pasteurización para definir el uso de leche pasteurizada en los BLH.

Teniendo en cuenta el objetivo del artículo, la información se presenta de manera narrativa en tablas de resumen de hallazgos. Para la comunicación de los resultados, se tuvieron en cuenta las recomendaciones de la declaración PRISMA ${ }^{(25,26)}$.

\section{RESULTADOS}

\section{Resultados de la búsqueda de literatura}

Se identificaron 577 títulos, se hizo una escogencia de artículos basados en el título y en el resumen, de los cuales se excluyeron 537 artículos que no cumplían los criterios de selección. Se revisaron 40 documentos en texto completo, de los cuales finalmente fueron incluidos 22. Los detalles del proceso de selección están sintetizados en la Figura 1 y las características de los documentos incluidos están en la Tabla 2.

De los 22 documentos seleccionados, tres exponían medidas sobre la atención de donantes y manejo de las muestras en relación con la actual pandemia ${ }^{(27-29)}$. Siete eran publicaciones de opinión y cartas al editor frente al tema de BLH y las medidas adoptadas basadas en experiencias y expresando diferentes posiciones ${ }^{(19,29-34)}$. Once eran informes sobre aspectos técnicos en los procesos biológicos en bancos de leche humana ${ }^{(17,23,24,36-43)}$, una publicación era una revisión sistemática acerca de la evidencia de métodos de pasteurización y esterilización en bancos de leche referente a infecciones virales ${ }^{(44)}$.

La revisión sistemática fue hecha por un solo autor, de 23.441 citas, en el proceso de selección finalmente fueron incluidos 108 artículos, estos exponen diferentes metodologías de pasteurización y pruebas realizadas en LH y leche no humana, así como pruebas para evaluar la presencia de virus en estas. Se presentó la evidencia sobre la variación de métodos de pasteurización con referencia a infecciones virales en bancos de leche y el proceso Holder ${ }^{(44)}$.

Los informes técnicos consistieron en reportes de análisis en laboratorios sobre diversos temas que eva- lúan la presencia del virus SARS en leche humana y los métodos de pasteurización ${ }^{(13,17,23,24,27,38,40-42,45)}$. Las cartas al editor hacían referencia a diferentes temas en relación con el manejo de bancos de leche humana ${ }^{(15,19,31-33,46)}$.

\section{Procesos de captación, selección y acompañamiento de donantes}

La información reportada recomienda la restricción del acompañamiento de la donante ${ }^{(33,47)}$, la evaluación de su estado de salud ${ }^{(13)}$, como aspectos importantes frente a la pandemia. También se hace énfasis en el manejo de prácticas de limpieza ${ }^{(14,28,29)}$ y la extracción de la leche en el centro de acopio $^{(33)}$. Se enfatiza en la evaluación del estado de salud de la donante, la higiene del envase antes y después de su uso ${ }^{(17,28)}$.

\section{Extracción y uso de la leche recolectada}

En relación con la extracción y conservación de la leche se exponen como elemento principal las medidas de protección de barrera descritas frente a la transmisión del SARS-CoV-02. El uso de leche homóloga de donantes sanas es recomendada idealmente como no pasteurizada, y LH heteróloga, pasteurizada si existe restricción por sospecha o enfermedad en la madre ${ }^{(31,33)}$. Esta información manifiesta los procesos que se realizaron en los países que publicaron sus experiencias.

\section{Transporte y almacenamiento de la leche en los BLH}

No se encontró información adicional a la presentada en el documento del Ministerio de Salud y Protección Social ${ }^{(17)}$ (Tabla 3).

\section{Transmisión vertical}

A partir de la evidencia de transmisión vertical viral por VIH en la $\mathrm{LH}^{(48)}$, se evaluó la presencia de MERS-CoV en leches en otros mamíferos durante la epidemia en el Medio Oriente en 2012, sin aclarar finalmente la forma de transmisión del virus ${ }^{(24)}$.

Con respecto a la pandemia un reporte refiere la presencia de RNA SARS-CoV-2 en una muestra de LH extraída durante el periodo de convalecencia de una mujer infectada por COVID-19 y su hijo, sin puntualizar la forma de contagio en éste ${ }^{(45)}$. La evaluación en otros fluidos corporales en puérperas con SARSCoV-2/COVID-19 no demostraron la presencia de infección $^{(49)}$. 
Tabla 2. Características de los documentos incluidos en la revisión

\begin{tabular}{|l|l|l|l|l|l|l|}
\hline $\begin{array}{c}\text { No. } \\
\text { Referencia }\end{array}$ & Fecha & País & \multicolumn{1}{|c|}{ Propósito } & $\begin{array}{c}\text { Población } \\
\text { Método, diseño o tipo de } \\
\text { publicación }\end{array}$ & $\begin{array}{c}\text { Tipo de intervención y } \\
\text { comparador }\end{array}$ & $\begin{array}{c}\text { ¿Cómo se miden } \\
\text { los resultados? }\end{array}$ \\
\hline $\mathbf{1}^{(27)}$ & $\begin{array}{c}\text { Marzo } \\
2020\end{array}$ & Inglaterra & $\begin{array}{l}\text { Presentar una postura frente a los } \\
\text { bancos de leche }\end{array}$ & Madres lactantes & $\begin{array}{l}\text { Revisión bibliográfica } \\
\text { Postura / posición? del autor }\end{array}$ & NA \\
\hline
\end{tabular}

Frente a la falta de evidencia de transmisión SARS-MERS por LM se plantea controversia de pasteurización, hay que evaluar clínicamente cada caso ante sospecha de infección, se sugiere observación por 2 semanas a la madre y suspender temporalmente aporte de leche.

\begin{tabular}{|c|c|c|c|c|c|c|c|}
\hline $\mathbf{2}^{(41)}$ & $\begin{array}{c}\text { Marzo } \\
2020\end{array}$ & China & Carta, anotación & $\begin{array}{l}\text { Pacientes sintomáticos } \\
\text { Experiencia personal }\end{array}$ & $\begin{array}{l}\text { Datos de muestras recogidas } \\
\text { Experiencia personal }\end{array}$ & $\begin{array}{l}\text { Evaluación de } \\
\text { carga viral en varios } \\
\text { momentos de infección }\end{array}$ & Carga viral \\
\hline \multicolumn{8}{|c|}{ *Variación de la carga viral de acuerdo con el inicio sintomático, detección en fómites } \\
\hline $3^{(17)}$ & $\begin{array}{c}\text { Marzo } \\
2019\end{array}$ & Colombia & $\begin{array}{l}\text { Establecer las orientaciones } \\
\text { conceptuales, técnicas y operativas } \\
\text { de los BLH en Colombia }\end{array}$ & Bancos de leche & $\begin{array}{l}\text { Revisión bibliográfica } \\
\text { Conceptos técnicos de acuerdo } \\
\text { con la normatividad vigente }\end{array}$ & NA & NA \\
\hline
\end{tabular}

*Hace una amplia descripción actualizada sobre el manejo de bancos de leche en Colombia, estableciendo las posturas y lineamientos técnicos que estos deben tener. Documento de referencia

\begin{tabular}{|l|l|l|l|l|l|l|}
\hline $\mathbf{4}^{(47)}$ & $\begin{array}{l}\text { Abril } \\
2020\end{array}$ & EE. UU. & $\begin{array}{l}\text { Establecer una posición frente a } \\
\text { los BL }\end{array}$ & Madres lactantes & Revisión bibliográfica & Revisión documentos \\
\hline
\end{tabular}

A partir de las experiencias aplicables con otras pandemias, se toma la postura de pasteurización de las alícuotas del LH. Evolución de los métodos de pasteurización, ante el riesgo de transmisión por la LH por contacto las medidas de protección con respecto a la diada, evaluación de los donadores de leche

\begin{tabular}{|c|c|c|c|c|c|c|c|}
\hline $5^{(13)}$ & $\begin{array}{c}\text { Marzo } \\
2020\end{array}$ & Italia & $\begin{array}{l}\text { Establecer una posición frente a } \\
\text { los BL }\end{array}$ & Madres lactantes & Revisión bibliográfica & Revisión documentos & NA \\
\hline \multicolumn{8}{|c|}{$\begin{array}{l}\text { Revisión bibliografía temática (1). Transmisión contacto, poco probable por fómites, ¿transmisión transparentaría?; depende más de la enfermedad de la madre que la transmisión de la } \\
\text { enfermedad al producto. RN (CV+), transmisión horizontal, infección pausiasintomática, (2) niños y lactantes, evidencia de transmisión de lg M en leche, papel protector), manejo de la } \\
\text { madre y el RN de acuerdo con el estado de salud: sano, sospechoso, infectado. Se revisan varias posturas de manejo de la madre y el niño: manejo de medidas protección. resumen de } \\
\text { estas }\end{array}$} \\
\hline $6^{(15)}$ & $\begin{array}{l}\text { Mayo } \\
2020\end{array}$ & UK & $\begin{array}{l}\text { Establecer una posición frente a } \\
\text { los BL }\end{array}$ & Madres lactantes & Revisión bibliográfica & Revisión documentos & NA \\
\hline
\end{tabular}

Parte de la posición que no hay aun la evidencia adecuada para el manejo de los bancos de leche. Se mantiene la postura que la lactancia prima sobre el riesgo, manejando las medidas de precaución, manteniendo todas las conductas que optimizan la continuidad de la lactancia: objetivo importante, mantener la nutrición de LH al neonato, evaluación medidas asépticas en $\mathrm{BL}$, desarrollo de estrategias para recolección de datos de experiencias de otros $\mathrm{BL}$

\begin{tabular}{|l|c|c|l|l|l|l|}
\hline $\mathbf{7}^{(11)}$ & $\begin{array}{c}\text { Enero } \\
2020\end{array}$ & EE. UU. & $\begin{array}{l}\text { Recomendaciones de manejo del } \\
\text { cuidado obstétrico y del RN bajo } \\
\text { pandemia }\end{array}$ & Maternas y RN & Revisión bibliográfica & Revisión documentos \\
\hline
\end{tabular}


Tabla 2. Características de los documentos incluidos en la revisión (continuación)

\begin{tabular}{|c|c|c|c|c|c|c|c|}
\hline $\begin{array}{c}\text { No. } \\
\text { Referencia }\end{array}$ & Fecha & País & Propósito & Población & $\begin{array}{l}\text { Método, diseño o tipo de } \\
\text { publicación }\end{array}$ & $\begin{array}{c}\text { Tipo de intervención y } \\
\text { comparador }\end{array}$ & $\begin{array}{l}\text { ¿Cómo se miden } \\
\text { los resultados? }\end{array}$ \\
\hline $8^{(24)}$ & 2014 & EE. UU. & $\begin{array}{l}\text { Evaluar la permanencia del virus } \\
\text { SARS en diferentes tipos de leche } \\
\text { de mamíferos }\end{array}$ & $\begin{array}{l}\text { Alícuotas de leches de } \\
\text { mamíferos. Evaluación del } \\
\text { proceso de pasteurización }\end{array}$ & Reporte de laboratorio & $\begin{array}{l}\text { Permanencia de virus } \\
\text { en leches pasteurizadas }\end{array}$ & NA \\
\hline
\end{tabular}

Ante el desconocimiento de la forma de transmisión del virus MERS-CoV en los humanos, establece la posibilidad de contagio por ingesta de productos contaminados por este. Evalúan la permanencia del virus en varios tipos de leche de mamíferos posterior al proceso de pasteurización como medida de protección ante la ingesta de productos contaminados

\begin{tabular}{|l|l|l|l|l|l|l|}
\hline 9(42) & 2006 & EE. UU. & $\begin{array}{l}\text { Presentar diversos métodos de } \\
\text { esterilización }\end{array}$ & $\begin{array}{l}\text { Alícuotas varias para } \\
\text { evaluar métodos diversos } \\
\text { de esterilización productos } \\
\text { sanguíneos y SARS }\end{array}$ & $\begin{array}{l}\text { Técnicas de laboratorio } \\
\begin{array}{l}\text { Técnicas de dilución } \\
\text { e inactivación viral en } \\
\text { diversos productos de } \\
\text { sangre y métodos de } \\
\text { esterilización }\end{array}\end{array}$ & $\begin{array}{l}\text { Comparación y } \\
\text { medición de títulos } \\
\text { virales }\end{array}$ \\
\hline
\end{tabular}

Ante el riesgo de contagio por transfusión de diversos productos sanguíneos y SARS se evaluó las diferentes técnicas de esterilización, y se deben emplear varios métodos de esterilización

\begin{tabular}{|c|c|c|c|c|c|c|c|}
\hline $10^{(28)}$ & $\begin{array}{l}\text { Mayo } \\
2020\end{array}$ & Brasil & $\begin{array}{l}\text { Ofrecer un resumen sobre el } \\
\text { manejo bancos de leche humana }\end{array}$ & Donadoras y receptores & Reporte medidas sanitarias & NA & NA \\
\hline \multicolumn{8}{|c|}{$\begin{array}{l}\text { Ruta de recolección, procesamiento, pasteurización y distribución de LH. Norma técnica 01/20, } 170320 \text { (Brasil): prácticas de limpieza del área, equipo para las donadoras, equipo para las } \\
\text { operarias, transporte, recepción y distribución }\end{array}$} \\
\hline $11^{(23)}$ & 2000 & EE. UU. & $\begin{array}{l}\text { Evaluación de la acción antiviral } \\
\text { para CMV y Rinovirus de la LM }\end{array}$ & $\begin{array}{l}\text { Alícuotas de LM en cultivos } \\
\text { celulares infectados con } \\
\text { CMV y Rinovirus, acción de } \\
\text { varios componentes con } \\
\text { actividad antiviral }\end{array}$ & Técnicas de laboratorio & $\begin{array}{l}\text { Técnicas de laboratorio } \\
\text { varias para evaluar } \\
\text { crecimiento viral }\end{array}$ & $\begin{array}{l}\text { Inhibición de placas } \\
\text { de crecimiento viral } \\
\text { en cultivos celulares }\end{array}$ \\
\hline
\end{tabular}

Se demostró parcialmente la inhibición del crecimiento de CMV en células mediante principalmente por la acción de la lactoferrina, también la presencia de IG A secretora neutralizó el crecimiento de rinovirus

\begin{tabular}{|l|l|l|l|l|l|l|}
\hline $\mathbf{1 2}^{(33)}$ & $\begin{array}{l}\text { Abril } \\
2020\end{array}$ & UK & Reflexiones sobre la actual pandemia & Bancos de leche, URN & Posición de pensamiento & NA \\
\hline
\end{tabular}

Comentando las dificultades que se tiene sobre la consecución de donantes de LM, y el riesgo para RN prematuros, lo que ha llevado a racionalizar el empleo de LM pasteurizadas para PT extremos. Y se requieren campañas, además se aumenta las dificultades de los donantes al aumentar la cantidad de requisitos para la donación de leche

\begin{tabular}{|l|c|c|l|l|l|l|}
\hline $\mathbf{1 3}^{(19)}$ & $\begin{array}{c}\text { Marzo } \\
2020\end{array}$ & EE. UU. & $\begin{array}{l}\text { Determina la postura frente a los } \\
\text { bancos de leche }\end{array}$ & $\begin{array}{l}\text { Bancos de leche, posibles } \\
\text { donantes de LH }\end{array}$ & Posición de pensamiento & NA \\
\hline
\end{tabular}

Se exponen diferentes experiencias en China, Italia y EE. UU. en la situación de donantes de leche, como se ha afectado la donación de leche frente al confinamiento desarrollado por la pandemia, y cuales estrategias se emplearon para poder continuar con la demanda de leche. Se expone que hay una posición diferente entre el CDC y WHO/UNICEF, con relación al uso de la leche humana, en el cual prima el principio de beneficio de la leche humana en la salud de los RN. Se recomienda las medidas de higiene en las madres donantes, y el manejo de madres PUS y aquellas infectadas por Cv19, en las últimas el uso de leche pasteurizada, al igual que envases pasteurizados individuales 
Tabla 2. Características de los documentos incluidos en la revisión (continuación)

\begin{tabular}{|l|l|l|l|l|l|l|}
\hline $\begin{array}{c}\text { No. } \\
\text { Referencia }\end{array}$ & Fecha & País & \multicolumn{1}{|c|}{ Propósito } & \multicolumn{1}{c|}{$\begin{array}{c}\text { Población } \\
\text { Método, diseño o tipo de } \\
\text { publicación }\end{array}$} & $\begin{array}{c}\text { Tipo de intervención y } \\
\text { comparador }\end{array}$ & $\begin{array}{c}\text { ¿Cómo se miden } \\
\text { los resultados? }\end{array}$ \\
\hline $\mathbf{1 4}^{(67)}$ & $\begin{array}{c}\text { Marzo } \\
2020\end{array}$ & EE. UU. & $\begin{array}{l}\text { Determinar postura frente a los } \\
\text { bancos de leche, manejo de } \\
\text { recipientes }\end{array}$ & $\begin{array}{l}\text { Bancos de leche, posibles } \\
\text { donantes de LH }\end{array}$ & $\begin{array}{l}\text { Posición de pensamiento } \\
\text { NA }\end{array}$ \\
\hline
\end{tabular}

Se propone desinfectar todos los recipientes que se reciban en los bancos de leche, dado que se desconoce quiénes están sanos y quiénes son portadores sanos, luego para disminuir el riesgo de contagio se hace en forma uniforme para todas las muestras que se reciban. Uso de todos los elementos de protección en forma usual y cuando haya sospecha de contagio,

\begin{tabular}{|l|c|c|l|l|l|l|}
\hline $15^{(29)}$ & $\begin{array}{c}\text { Marzo } \\
2020\end{array}$ & EE. UU. & $\begin{array}{l}\text { Presentar el manejo de material } \\
\text { por trabajadores de la salud, para } \\
\text { disminuir el riesgo de infección por } \\
\text { COVID-19 }\end{array}$ & Trabajadores de la salud & $\begin{array}{l}\text { Revisión bibliográfica y } \\
\text { recomendaciones }\end{array}$ & NA \\
\hline
\end{tabular}

Recomendaciones del uso de objetos de protección de gotas y contacto de superficies, líquidos con posible contacto, transporte de muestras, manejo de pacientes externos e internos

\begin{tabular}{|c|c|c|c|c|c|c|c|}
\hline $16^{(45)}$ & $\begin{array}{l}\text { Mayo } \\
2020\end{array}$ & Alemania & $\begin{array}{l}\text { Reportar la presencia de Covid } 19 \\
\text { en leche }\end{array}$ & Madres lactantes y RN & Reporte laboratorio & NA & NA \\
\hline \multicolumn{8}{|c|}{ Se reporta la presencia de COVID en la leche extraída de una madre con COVID + y síntomas en su bebé, durante varios días. Solo dos casos, un caso positivo } \\
\hline $17^{(40)}$ & $\begin{array}{l}\text { Abril } \\
2020\end{array}$ & EE. UU. & $\begin{array}{l}\text { Revisión evidencia de la presencia } \\
\text { de SARS-CoV19 en la LM }\end{array}$ & Madres lactantes y RN & $\begin{array}{l}\text { Revisión bibliográfica y } \\
\text { recomendaciones }\end{array}$ & NA & NA \\
\hline
\end{tabular}

Aún se desconocen los modelos de transmisión del SARS-CoV19, información muy limitada de la transmisión vertical viral, hay reportes con casos aislados, unos positivos y otros negativos, se conoce exposiciones previas de infecciones virales transmitidas por la leche humana, como el VIH citomegalovirus y el virus linfotrópico tipo T. Hasta el momento no hay evidencia de transmisión del virus SARS-CoV19 en LH, presentan casos de maternas con la presencia viral en fluidos corporales en 9 estudios, no conclusiva en LH. La presencia del receptor de membrana NL63, esencial para la replicación del virus está presente en el tejido mamario, dando la posibilidad de transmisión del virus en la leche, sin descartar otros mecanismos de infección

\begin{tabular}{|c|c|c|c|c|c|c|c|}
\hline $18^{(68)}$ & $\begin{array}{c}\text { Marzo } \\
2020\end{array}$ & EE. UU. & Carta, anotación & NA & NA & NA & NA \\
\hline \multicolumn{8}{|c|}{ Posición más centrada frente a la publicación de Mirelly, refiere estar de acuerdo con el manejo de las muestras } \\
\hline $19^{(57)}$ & $\begin{array}{l}\text { Mayo } \\
2020\end{array}$ & Canadá & $\begin{array}{l}\text { Revisión sistemática sobre los } \\
\text { procesos de pasteurización de LH }\end{array}$ & & $\begin{array}{l}\text { Revisión sistemática } \\
\text { Descripción taxonómica de } \\
\text { infección viral LM; sinónimos y } \\
\text { conceptos LM; pasteurización y } \\
\text { LM }\end{array}$ & $\begin{array}{l}\text { Revisión bibliográfica } \\
\text { y recomendaciones } \\
\text { en MEDLINE, Embase y } \\
\text { literatura gris. Artículos } \\
\text { publicados hasta abril } \\
2020\end{array}$ & $\begin{array}{l}\text { Estudios } \\
\text { cualitativos, } \\
\text { evaluación de la } \\
\text { carga viral posterior } \\
\text { al proceso de } \\
\text { pasteurización } \\
\text { o virus vivos } \\
\text { detectados }\end{array}$ \\
\hline
\end{tabular}

A partir de los 108 artículos seleccionados en la revisión, hace apreciación de la experiencia del método de pasteurización frente a la variedad de virus presentes en la LM, presenta datos de diferentes valores de temperatura para pasterurizar evaluados en $L M$, estudios que evalúan pruebas virales en la $L M$ y otras matrices. El método Holder de pasteurización $\left(62,5^{\circ} \mathrm{C}\right.$ durante $30^{\prime}$ ), ofrece la mayor evidencia en la literatura publicada. Hay diversidad métodos y técnicas que limitan la comparación de resultados. El estudio fue realizado por un solo investigador, hay riesgo de sesgo. 
Tabla 2. Características de los documentos incluidos en la revisión (continuación)

\begin{tabular}{|l|l|l|l|l|l|l|}
\hline $\begin{array}{c}\text { No. } \\
\text { Referencia }\end{array}$ & Fecha & País & \multicolumn{1}{|c|}{ Propósito } & $\begin{array}{c}\text { Población } \\
\text { Método, diseño o tipo de } \\
\text { publicación }\end{array}$ & $\begin{array}{c}\text { Tipo de intervención y } \\
\text { comparador }\end{array}$ & $\begin{array}{c}\text { ¿Cómo se miden } \\
\text { los resultados? }\end{array}$ \\
\hline $\mathbf{2 0}^{(32)}$ & $\begin{array}{c}\text { Mayo } \\
2020\end{array}$ & Italia & Carta, anotación & NA & NA & NA \\
\hline
\end{tabular}

Posibilidad de emplear otros métodos de limpieza de los contenedores, se habla de la experiencia en Roma, que es diferente a la de Milán, hace referencia al costo de emplear hipoclorito es mucho menor que otros desinfectantes

\begin{tabular}{|c|c|c|c|c|c|c|c|}
\hline $2 \mathbf{1}^{(38)}$ & $\begin{array}{c}\text { Marzo } \\
2020\end{array}$ & China & $\begin{array}{l}\text { Evaluar la presencia del virus } \\
\text { SARS-Cov-2 en diferentes medios y } \\
\text { condiciones físicos }\end{array}$ & NA & $\begin{array}{l}\text { Detección de la presencia del } \\
\text { virus SARS-Cov-2 en diferentes } \\
\text { medios y condiciones físicos por } \\
\text { medio de RT-PCR. Carta al editor }\end{array}$ & Reporte & $\begin{array}{l}\text { Presencia del virus } \\
\text { por medio de } \\
\text { cultivo y RT-PCR }\end{array}$ \\
\hline \multicolumn{8}{|c|}{ Se demostró que el virus es estable en medios favorables, pero que es sensible a los métodos de desinfección } \\
\hline $\mathbf{2 2}^{(39)}$ & $\begin{array}{l}\text { Mayo } \\
2020\end{array}$ & Italia & $\begin{array}{l}\text { Evaluar el proceso de } \\
\text { pasteurización Holder (HoP) frente } \\
\text { a la técnica de alta temperatura } \\
\text { por corto tiempo (HTST) y la de } \\
\text { alta presión (HPP) con relación a } \\
\text { la conservación de los elementos } \\
\text { bioactivos de la LH }\end{array}$ & Reporte técnico & $\begin{array}{l}\text { Evaluación técnica en laboratorio } \\
\text { sobre muestras de leche }\end{array}$ & $\begin{array}{l}\text { Comparativo de } \\
\text { indicadores de calidad } \\
\text { para actividad biológica } \\
\text { de protección de } \\
\text { la leche materna } \\
\text { (lactoferrina, Ig A) } \\
\text { teniendo como base el } \\
\text { método HoP frente a } \\
\text { los otros dos métodos } \\
\text { estudiados }\end{array}$ & $\begin{array}{l}\text { Se presentan los } \\
\text { resultados de } \\
\text { medición de niveles } \\
\text { de lactoferrina } \\
\text { e lg A para los } \\
\text { diferentes medios } \\
\text { de pasteurización }\end{array}$ \\
\hline
\end{tabular}

*Hallazgos principales y temas tratados en los artículos revisados.

NA: no aplica; HC: historia clínica; CMV: citomegalovirus; BLH: bancos de leche humana; RN: recién nacidos; URN: unidades de recién nacidos. 
Tabla 3. Comparación de las orientaciones técnicas el Ministerio de Salud y los hallazgos de la literatura

\begin{tabular}{|c|c|}
\hline Documento actual del Ministerio de Salud de Colombia ${ }^{(17)}$ & $\begin{array}{c}\text { Propuesta a partir de los hallazgos de la búsqueda de } \\
\text { literatura }\end{array}$ \\
\hline \multicolumn{2}{|l|}{ Procesos de captación, selección y acompañamiento de donantes } \\
\hline Puede ser acompañada & Restricción del acompañamiento por un familiar ${ }^{(33,47)}$. \\
\hline Evaluación del estado de salud de la madre. & $\begin{array}{l}\text { Evaluación del estado de salud de la madre: protocolo de } \\
\text { examen y llenado de cuestionario para evaluar riesgo de } \\
\text { infección, si se requiere toma de muestra en sangre para } \\
\text { evaluar infección por COVID-19(13). }\end{array}$ \\
\hline $\begin{array}{l}\text { Manejo de las prácticas de limpieza: lavado de manos, uso de } \\
\text { gorro, máscara y blusa. }\end{array}$ & $\begin{array}{l}\text { Manejo de las prácticas de limpieza: lavado de manos, } \\
\text { uso de gorro, máscara y blusa }{ }^{(15,27-29)} \text {. }\end{array}$ \\
\hline $\begin{array}{l}\text { Extracción de la leche en casa o fuera del área del banco de leche } \\
\text { humana. }\end{array}$ & $\begin{array}{l}\text { La extracción de leche autóloga en lo posible se realiza } \\
\text { en el centro de acopio del banco de leche } e^{(33)} \text { aceptando } \\
\text { leche humana heteróloga pasteurizada }{ }^{(33)} \text {. Las donaciones } \\
\text { se difieren en su uso si hay sospecha de infección hasta } \\
\text { su resultado }{ }^{(31)}\end{array}$ \\
\hline Evaluación de la donante. & $\begin{array}{l}\text { Evaluación de la donante: clasificación de acuerdo con el } \\
\text { riesgo de infección. Se debe informar sobre las políticas } \\
\text { de protección y selección de las muestras }{ }^{(27,31)} \text {. }\end{array}$ \\
\hline \multicolumn{2}{|l|}{ Extracción y conservación de la leche y manejo de alícuotas y envases } \\
\hline Recolección en casa o por servicio a domicilio. & $\begin{array}{l}\text { Se acepta la donación de leche para uso heterólogo } \\
\text { evaluando si o no el proceso pasteurización de este y la } \\
\text { evaluación de la donante }{ }^{(31,33)} \text {. }\end{array}$ \\
\hline Rotulado del frasco con toda la información pertinente. & ídem. \\
\hline $\begin{array}{l}\text { Se mantienen las características de los envases: que sean } \\
\text { resistentes al lavado, desinfección y esterilización. }\end{array}$ & Ídem. \\
\hline Que sean químicamente inertes para el transporte de leche. & Ídem. \\
\hline Que tengan un sellado hermético. & Ídem. \\
\hline $\begin{array}{l}\text { Higiene del frasco previo y posterior a su uso con hipoclorito de } \\
\text { sodio } 1: 10(0,5 \%)\end{array}$ & $\begin{array}{l}\text { Higiene del frasco previo y posterior a su uso con } \\
\text { hipoclorito de sodio } 1: 10(0,5 \%)^{(67)} \text { o alcohol al } 70 \%{ }^{(28)} \\
\text { por el riesgo de permanencia del virus en superficies por } \\
\text { un tiempo no determinado }{ }^{(38,51)} \text { por lo cual se recomienda } \\
\text { el proceso previo a la manipulación del producto. }\end{array}$ \\
\hline $\begin{array}{l}\text { Se recomienda mantener las alícuotas de acuerdo con la norma } \\
\text { BLH-IFF/NT } 19.11^{(28)} \text { guardada a una temperatura de }-3^{\circ} \mathrm{C} \text { y que } \\
\text { no duren más de seis horas para el proceso de pasteurización }{ }^{(17,28)} \text {. }\end{array}$ & Ídem. \\
\hline \multicolumn{2}{|l|}{ Transporte y almacenamiento de la leche en los BLH } \\
\hline $\begin{array}{l}\text { Condiciones de limpieza y desinfección del embalaje de } \\
\text { transporte. }\end{array}$ & Ídem. \\
\hline $\begin{array}{l}\text { Temperatura de cajas isotérmicas a }-3^{\circ} \mathrm{C} \text {, con registro de } \\
\text { temperatura en el formato correspondiente. }\end{array}$ & Ídem. \\
\hline Integridad de los envases, cumplimiento de las condiciones físicas. & Ídem. \\
\hline $\begin{array}{l}\text { Rótulo de información requerida con el nombre del donante, } \\
\text { fecha y hora de la primera extracción. }\end{array}$ & Ídem. \\
\hline Recepción de leches extraídas en el domicilio o en el BLH. & $\begin{array}{l}\text { Se recibirán leches extraídas por donantes evaluadas para } \\
\text { uso heterólogo y homólogo } \mathrm{BLH}^{(13,33)} \text {. }\end{array}$ \\
\hline $\begin{array}{l}\text { Limpieza con alcohol a } 70 \% \text {, o con hipoclorito de sodio 1:10 } \\
(0,5 \%)^{(17)} \text {. }\end{array}$ & $\begin{array}{l}\text { Limpieza con alcohol a } 70 \% \text {, o con hipoclorito de } \\
\text { sodio } 1: 10(0,5 \%)^{(67)} \text {. En este punto hay discusión } \\
\text { sobre extremar las medidas de limpieza del frasco, se } \\
\text { considera la posibilidad del costo neto de los productos } \\
\text { empleados }^{(68)} \text {. }\end{array}$ \\
\hline $\begin{array}{l}\text { Condiciones de limpieza y desinfección del embalaje de } \\
\text { transporte. }\end{array}$ & Ídem. \\
\hline
\end{tabular}




\section{Pasteurización}

Un documento evaluó la literatura referente al efecto de la pasteurización térmica en la carga viral y la supervivencia de SARS-CoV-2 en la leche humana; presenta información que evalúa diversas variaciones técnicas de pasteurización con respecto al método Holder y al impacto que tendrían en la esterilización de la leche y la carga viral, enfocándose en el tema de transmisión viral ${ }^{(44)}$.

\section{DISCUSIÓN}

La presente revisión muestra los cambios y las adaptaciones que se realizaron en los bancos de leche durante la pandemia por SARS-CoV-2/COVID-19 sobre temas como la selección y evaluación de donantes, el papel que tienen los BLH en prematuros, la importancia de definir el empleo de leche autóloga o heteróloga con el objeto de preservar las cualidades no solo nutricionales sino biológicas de la leche humana en esta población.

Dada la complejidad del tema, se desarrolló una iniciativa mundial para compartir información acerca del manejo de los BLH frente a la actual pandemia, teniendo en cuenta la diversidad de información, conceptos y experiencias para buscar la unificación de criterios $^{(15)}$.

$\mathrm{Al}$ demostrarse la transmisión del VIH en la $\mathrm{LH}^{(48,50)}$, los procesos de pasteurización en el manejo de muestras en los BLH adquirieron relevancia. Frente a la posibilidad de transmisión viral en la leche, las experiencias en 2002 por epidemias respiratorias por coronavirus, mostraron que la transmisión viral se da principalmente por partículas inhaladas o contacto físico en superficies ${ }^{(51)}$. En 2012 se sospechó la posibilidad de transmisión de un coronavirus (MERS) ${ }^{(24)}$ a través de fluidos como la leche, por lo cual se evaluaron leches de mamíferos sometidas a diferentes temperaturas indicando la utilidad de la pasteurización en la disminución de la carga viral.

Frente al riesgo de la presencia del virus SARS-CoV-2 en fluidos corporales ${ }^{(41)}$, se plantea la importancia de su detección en el manejo de los BLH. Un reporte muestra la presencia del virus identificado por Rt-qPCR SARSCoV-2 en muestras de casos aislados, pero sin aclarar la forma de contagio ${ }^{(45)}$. Igualmente se ha reportado la presencia de inmunoglobulinas Ig G y M contra el virus SARS-CoV-2 en recién nacidos de horas, pero no en la LM usada por estos neonatos, lo cual sugiere la posibilidad de que los títulos de cargas virales no puedan ser detectados en la leche materna secretada ${ }^{(52)}$.
Una revisión sobre transmisión viral de SARS$\mathrm{CoV}-2$ en la $\mathrm{LH}^{(40)}$, no reportó evidencia de su transmisión. Tampoco se reporta transmisión viral vertical en los recién nacidos en la atención de mujeres gestantes al inicio de la pandemia en China ${ }^{(1)}$. Es esencial tener en cuenta que el SARS-CoV-2 es un virus encapsulado RNA que requiere el receptor ACE2, presente en el tejido mamario, para ingresar a las células y desarrollar así la enfermedad COVID-19(40).

Hasta el momento de la actual revisión, no se reportaba evidencia concluyente sobre el riesgo de contagio viral directo en la leche humana ${ }^{(24,41,52)}$.

Teniendo en cuenta lo anterior, hay diversas opiniones frente al uso de LHD en prematuros y el proceso de pasteurización. La LH ofrece beneficios por sus compuestos bioactivos no nutricionales y nutricionales. $\mathrm{La}$ pasteurización tipo Holder (HoP) es el método estandarizado internacional más utilizado en los BLH sobre el cual existe la mayor evidencia con respecto al control biológico infeccioso viral y bacteriano. Sin embargo, el proceso de pasteurización presenta como consecuencia la disminución de la capacidad biológica protectora ${ }^{(20)}$ al producir cambios en la composición química en las proteínas que conforman la $\mathrm{LH}^{(37)}$. Se alteran las moléculas que tienen propiedades biológicas inmunológicas anti-infecciosas, como inmunoglobulinas, lactoferrina y proteínas con propiedades enzimáticas (lipoproteínas), pero se mantiene la composición nutricional ${ }^{(20)}$.

Debido a la importancia que tienen los factores bioactivos no nutricionales en prematuros, desde hace una década se viene desarrollando investigación sobre diferentes métodos de pasteurización con respecto al estándar de HoP. Sin embargo, la variabilidad de los reportes técnicos, los equipos ${ }^{(18,20,54,55)}$, y las pruebas realizadas bajo condiciones técnicas en laboratorios de investigación, tanto en leche humana como de mamíferos, produce variabilidad en las conclusiones finales al momento de elegir un método frente a otro ${ }^{(37)}$.

Actualmente los métodos que podrían ofrecer ventajas en este sentido frente a HoP, son el de temperatura alta por corto tiempo $(\mathrm{HTST})^{(56)}$ y el proceso de alta presión (HPP $)^{(57)}$, los cuales evidencian una menor variabilidad y una mayor conservación de los factores bioactivos no nutricionales de la $\mathrm{LH}$ con referencia a la respuesta inmune y la actividad de control de infecciones $^{(30,39,43,55,56)}$. Sin embargo, dada la poca disponibilidad comercial de estos equipos para el uso en BLH, la evidencia de su uso también se encuentra limitada.

Teniendo en cuenta que la función principal de los BLH es la disponibilidad de LH para su uso en prema- 
turos a través de LHD, las circunstancias de la actual pandemia afectan de forma importante el recurso de donantes, poniendo en riesgo la funcionabilidad de los mismos $^{(58)}$, por lo que se requiere desarrollar estrategias activas en cada región para mitigar la posible escasez de donantes, dadas las consecuencias graves, no solo inmediatas para una población vulnerable como son los recién nacidos prematuros, sino las consecuencias sociales y económicas que de ello puede esperarse ${ }^{(59-61)}$.

Como medidas principales de protección contra la infección se hace énfasis en el uso de LH autóloga y en garantizar el buen estado de salud de la donante ${ }^{(14)}$. Sin embargo, si las condiciones de la donante no lo permiten, la OMS y la UNICEF aceptan el uso de leche humana pasteurizada.

Aunque a la fecha no hay evidencia concluyente sobre la transmisión del virus a través de la leche $\mathrm{e}^{(15,38,45)}$, en caso de sospecha de infección por SARS-CoV-2, se recomienda el uso de leche humana pasteurizada. Esta consideración es sensible para el uso exclusivo en prematuros, como población infantil vulnerable en la actual circunstancia de pandemia ${ }^{(60-66)}$, con objeto de no limitar el uso de LH no pasteurizada, y otorgar los beneficios no solo nutricionales, sino biológicos para esta población. Luego se hace necesario evaluar cada caso en forma individual para ofrecer el máximo beneficio.

$\mathrm{Al}$ considerar las pautas técnicas propuestas por el Ministerio de Salud y Protección Social de Colombia, con los hallazgos de la literatura obtenidos en esta revisión, se pueden hacer sugerencias que contribuyen a la prevención de la transmisión del virus SARS-CoV-2. Estos se agruparon en tres categorías: reclutamiento de donantes, extracción, conservación, manejo de alícuotas y contenedores; y pasteurización de leche en el BLH. La Tabla 3 presenta un resumen comparativo de las pautas del Ministerio y la propuesta basada en los hallazgos de la literatura.

Es importante tener en cuenta que toda esta información es un proceso que cambia de manera constante frente a la aparición de nuevas evidencias, y por tanto, lo expresado en este documento invita a la evaluación permanente de los métodos de funcionamiento en cada institución con relación a los BLH. En consecuencia y de acuerdo con las posibilidades técnicas, administrativas y económicas, se recomienda adoptar mejores prácticas preventivas encaminadas a disminuir el riesgo de contagio por SARS-CoV-2 tanto de los donantes y operarios como del destinatario final que son los recién nacidos. De esta forma se está estimulando, también, una de sus funciones principales: el apoyo a la lactancia.

\section{CONCLUSIÓN}

A la fecha no se ha puesto en evidencia la transmision vertical del virus SARS-COV-2. Hay que evaluar el estado de salud de la madre en el caso de un recién nacido prematuro para el uso de LH autóloga. De igual manera, evaluar la salud de las mujeres donantes para obtener LHD, reforzar los procesos de protección del personal del BLH para garantizar su seguridad, el manejo de las alícuotas para su uso final, y en desarrollar estrategias activas en la promoción de la lactancia en la comunidad de cada área con BLH.

\section{Financiación}

Ninguna

\section{Conflicto de intereses}

Los autores declaramos no tener conflicto de interés.

\section{Agradecimientos}

A los compañeros de la RED INLAMA: Angelina Perna Chaux, Nayide Barahona Guzmán, Guiomar Hernández Álvarez, Faride Rodríguez Diaz, Doris Amparo Parada Rico, Viviana Barraza Figueroa, Jacqueline Hernández Escolar, Sandra Mondragón Bohórquez, Ysis Roa Meggo, Ana Yépez Barreto, Elida Salcedo Molinares, miembros de la red de investigadores en lactancia que apoyaron en informar el desarrollo de publicaciones durante el tiempo de búsqueda de los artículos.

\section{Declaración de autoría}

AJO búsqueda, recolección, evaluación de literatura, redacción del documento. FSM evaluación crítica de los artículos, desarrollo y evaluación del artículo. RSL, CDL, NCL, IRH, DAPR, búsqueda de literatura, evaluación del artículo. Todos los autores revisaron el artículo y validaron su versión final.

\section{Referencias bibliográficas}

1. Adhikari SP, Meng S, Wu Y-J, Mao Y-P, Ye R-X, Wang Q-Z, et al. Epidemiology, causes, clinical manifestation and diagnosis, prevention and control of coronavirus disease (COVID-19) during the early outbreak period: a scoping review. Infect Dis Poverty. 2020;9: 29. doi: https://doi.org/10.1186/s40249020-00646-x.

2. COVID-19 Host Genetics Initiative. The COVID-19 Host Genetics Initiative, a global initiative to elucidate the role of 
host genetic factors in susceptibility and severity of the SARSCoV-2 virus pandemic. Eur J Hum Genet. 2020;28(6):715-8. doi: https://doi.org/10.1038/s41431-020-0636-6.

3. Lu R, Zhao X, Li J, Niu P, Yang B, Wu H, et al. Genomic characterisation and epidemiology of 2019 novel coronavirus: implications for virus origins and receptor binding. Lancet. 2020;395(10224):565-74. doi: https://doi.org/10.1016/ S0140-6736(20)30251-8.

4. Gorbalenya AE, Baker SC, Baric RS, de Groot RJ, Drosten $\mathrm{C}$, Gulyaeva AA, et al. The species Severe acute respiratory syndrome- related coronavirus : classifying 2019-nCoV and naming it SARS-CoV-2. Nat Microbiol. 2020: 536-544. doi: https://doi.org/10.1038/s41564-020-0695-Z.

5. Jiang S, Shi Z, Shu Y, Song J, Gao GF, Tan W, et al. A distinct name is needed for the new coronavirus. Lancet. 2020; 395(10228): 949. doi: https://doi.org/10.1016/S01406736(20)30419-0.

6. World Health Organization (WHO). Naming the coronavirus disease (COVID-19) and the virus that causes it [Internet]. WHO; 2020 [citado 2 de abril de 2020]. Disponible en: https://www.who.int/emergencies/diseases/novel-coronavirus-2019/technical-guidance/naming-the-coronavirusdisease-(covid-2019)-and-the-virus-that-causes-it.

7. Rabi FA, Al Zoubi MS, Kasasbeh GA, Salameh DM, Al-Nasser AD. SARS-CoV-2 and Coronavirus Disease 2019: What we know so far. Pathogens. 2020;9(3):231. doi: https://doi. org/10.3390/pathogens 9030231 .

8. Cui J, Li F, Shi Z-L. Origin and evolution of pathogenic coronaviruses. Nat Rev Microbiol. 2019;17(3):181-92. doi: http://dx.doi.org/10.1038/s41579-018-0118-9.

9. Guan W-J, Liang W-H, Zhao Y, Liang H-R, Chen Z-S, Li Y-M, et al. Comorbidity and its impact on 1590 patients with Covid19 in China: A nationwide analysis. Eur Respir J. 2020;55(5): 2000547. doi: https://doi.org/10.1183/13993003.00547-2020.

10. The Lancet. Redefining vulnerability in the era of COVID19. Lancet. 2020;395(10230):1089. doi: http://dx.doi. org/10.1016/S0140-6736(20)30757-1.

11. Center for Disease Control and Prevention (CDC). People at Higher Risk for Severe Illness. People with certain medical conditions [Internet].CDC; August 14, 2020 [citado 2 de junio de 2020]. Disponible en: https://www.cdc.gov/ coronavirus/2019-ncov/need-extra-precautions/groups-athigher-risk.html.

12. BBC. Coronavirus confirmed as pandemic by World Health Organization. [Internet]. 11 de marzo de 2020 [Fecha de consulta: Mayo 25 2020]. Disponible en: https://www.bbc.com/ news/world-51839944.

13. Davanzo R, Moro G, Sandri F, Agosti M, Moretti C, Mosca F. Breastfeeding and coronavirus disease-2019: Ad interim indications of the Italian Society of Neonatology endorsed by the Union of European Neonatal \& Perinatal Societies. Matern Child Nutr. 2020;16(3):e13010. doi: http://dx.doi. org/10.1111/mcn.13010.
14. Centers for Disease Control and Prevention (CDC). Safety in Maternity Care [Internet]. CDC; January 5th, 2020 [citado 10 de mayo de 2020]. Disponible en: https://www.cdc.gov/ breastfeeding/recommendations/safety-in-maternity-care. html.

15. Shenker N, Virtual Collaborative Network of Human Milk Banks and Associations. Maintaining safety and service provision in human milk banking: a call to action in response to the COVID-19 pandemic. Lancet Child Adolesc Health. 2020;4(7):484-85. doi: http://dx.doi.org/10.1016/S23524642(20)30134-6.

16. Ministerio de Salud. Banco de Leche humana en Colombia [Internet]. [Fecha de consulta 2 de junio de 2020]. Disponible en: https://www.minsalud.gov.co/sites/rid/ Lists/BibliotecaDigital/RIDE/VS/PP/SNA/donacion-bancos-de-leche-humana-mayo-2015.pdf.

17. Dirección de Promoción y Prevención.Subdirección de Salud Nutricional, Alimentos y Bebidas. Lineamientos Técnicos para la Estrategia de Bancos de Leche Humana en Colombia Dirección de Promoción y Prevención [Internet]. Ministerios de Salud y Protección Social; Marzo de 2019. [Fecha de consulta: Marzo 20 2020]. Disponible en: https://actualisalud. com/wp-content/uploads/2019/03/Lineamientos-técnicosbanco-de-leche-humana.pdf.

18. Peila C, Moro GE, Bertino E, Cavallarin L, Giribaldi M, Giuliani $\mathrm{F}$, et al. The effect of holder pasteurization on nutrients and biologically-active components in donor human milk: A review. Nutrients. 2016;8(8):477. doi: https://doi. org/10.3390/nu8080477.

19. Marinelli KA. International Perspectives Concerning Donor Milk Banking During the SARS-CoV-2 (COVID-19) Pandemic. J Hum Lact. 2020;36(3):492-97. doi: https://doi. org/10.1177/0890334420917661.

20. Peila C, Emmerik NE, Giribaldi M, Stahl B, Ruitenberg JE, van Elburg RM, et al. Human milk processing: A systematic review of innovative techniques to ensure the safety and quality of donor milk.J Pediatr Gastroenterol Nutr. 2017;64(3):353-61. doi: https://doi.org/10.1097/MPG.0000000000001435.

21. Munn Z, Peters MDJ, Stern C, Tufanaru C, McArthur A, Aromataris E. Systematic review or scoping review? Guidance for authors when choosing between a systematic or scoping review approach. BMC Med Res Methodol. 2018;18(1):143. doi: https://doi.org/10.1186/s12874-018-0611-x.

22. Joanna Briggs Institute. Apprais tools use JBI Syst Rev [Internet]. 2017;1-7. [Fecha de consulta: 2 de junio 2020] Disponible en: https://joannabriggs.org/ebp/critical_ appraisal_tools.htlm.

23. Clarke NM. May JT. Effect of antimicrobial factors in human milk on rhinoviruses and milk born cytomegalovirus in vitro. J Med Microbiol. 2000;49(8):719-23. doi: https://doi. org/10.1099/0022-1317-49-8-719.

24. van Doremalen N, Bushmaker T, Karesh WB, Munster VJ. Stability of middle east respiratory syndrome coronavirus in 
milk. Emerg Infect Dis. 2014;20(7):1263-4. doi: https://doi. org/10.3201/eid2007.140500.

25. Liberati A, Altman DG, Tetzlaff J, Mulrow C, Gøtzsche PC, Ioannidis JPA, et al. The PRISMA statement for reporting systematic reviews and meta-analyses of studies that evaluate healthcare interventions: explanation and elaboration. BMJ. 2009;339: b2700. doi: https://doi.org/10.1136/bmj.b2700.

26. Tricco AC, Lillie E, Zarin W, O’Brien KK, Colquhoun $\mathrm{H}$, Levac D, et al. PRISMA extension for scoping reviews (PRISMA-ScR): Checklist and explanation. Ann Intern Med. 2018;169(7):467-73. doi: https://doi.org/10.7326/M180850.

27. European Milk Bank Association (EMBA). COVID-19: EMBA Position Statement. [Internet]. EMBA; February 25th, 2020. [Fecha de consulta: 11 de mayo de 2020]. Disponible en: https://europeanmilkbanking.com/covid-19-emba-position-statement/.

28. Rede Global de Bancos de Leite Humano. Rede Iberoamericana enfrentando o COVID-19: Boas Práticas em Bancos de Leite Humano [Internet]. rBLH Brasil. 2020 [Fecha de consulta: 15 de mayo de 2020]. Disponible en: https://rblh.fiocruz.br/rede-ibero-americana-enfrentando-ocovid-19-boas-praticas-em-banco-de-leite-humano.

29. World Health Organization (WHO). Infection prevention and control during health care when COVID-19 is suspected: interim guidance [Internet]. World Health Organization; 2020. [Fecha de consulta: 2 de junio de 2020]. Disponible en: https://apps.who.int/iris/handle/10665/331495.

30. Kleist SA, Knoop KA. Understanding the Elements of Maternal protection from Systemic Bacterial Infections during Early Life. Nutrients. 2020; 14(12): 1045; doi: https://doi. org/10.3390/nul12041045.

31. Jayagobi PA, Mei Chien C. Maintaining a Viable Donor Milk Supply During the SARS-CoV-2 (COVID-19) Pandemic.JHum Lact. 2020. doi: https://doi.org/10.1177/0890334420931828.

32. De Rose DU, Reposi MP, Amadio P, Auriti C, Dall'Oglio I, Corsetti T, et al. Use of Disinfectant Wipes to Sanitize Milk's Containers of Human Milk Bank During COVID-19 Pandemic. J Hum Lact. 2020;36(3): 547-49. doi: https://doi. org/10.1177/0890334420924639.

33. Furlow B. US NICUs and donor milk banks brace for COVID-19. Lancet Child Adolesc Health. 2020;4(5):355. doi: https://doi.org/10.1016/S2352-4642(20)30103-6.

34. HMBANA.org. Milk Banling and COVID 19 [Internet]. [citado 15 de mayo de 2020].p. 1-3. Disponible en: https:// www.texasmilkbank.org/.

35. Berveiller P, Guerby P, Garabedian C. COVID19 and Breastfeeding: Not That Simple. J Hum Lact. 2020;36(2): 369-70. doi: https://doi.org/10.1177/0890334420917102.

36. Kampf G, Todt D, Pfaender S, Steinmann E. Persistence of coronaviruses on inanimate surfaces and their inactivation with biocidal agents. J Hosp Infect. 2020;104(3):246-51. doi: https://doi.org/10.1016/j.jhin.2020.01.022.
37. Wesolowska A, Sinkiewicz-Darol E, Barbarska O, BernatowiczLojko U, Borszewska-Kornacka MK, van Goudoever JB. Innovative techniques of processing human milk to preserve key components. Nutrients. 2019;11(5):1169. doi: https:// doi.org/10.3390/nu11051169.

38. Chin AWH, Chu JTS, Perera MRA, Hui KPY, Yen H-L, Chan MCW, et al. Stability of SARS-CoV-2 in different environmental conditions. Lancet Microbe. 2020;1(1):e10. doi: https:// doi.org/10.1016/S2666-5247(20)30003-3.

39. Aceti A, Cavallarin L, Martini S, Giribaldi M, Vitali F, Ambretti S, Zambrini V, et al. Effect of alternative pasteurization techniques on human milk's bioactive proteins. J Pediatr Gastroenterol Nutr. 2020;70(4):508-12. doi: https://doi. org/10.1097/MPG.0000000000002598.

40. Lackey K, Pace R, Willams J, Bode L, Donovan Sh, Järvinen K, Seppo A, Raiten D, Meeham C, McGuire M MGM. SARSCo-V -2 and human milk: what is the evidence? MdedRxiv. 2020;1-22.

41. Pan Y, Zhang D, Yang P, Poon LLM, Wang Q. Viral load of SARS-CoV-2 in clinical samples. Lancet Infect Dis. 2020;20(4):411-12. doi: http://dx.doi.org/10.1016/S14733099(20)30113-4.

42. Darnell MER, Taylor DR. Evaluation of inactivation methods for severe acute respiratory syndrome coronavirus in noncellular blood products. Transfusion. 2006;46(10):1770-7. doi: https://doi.org/10.1111/j.1537-2995.2006.00976.x.

43. Gayà $\mathrm{A}$, Calvo $\mathrm{J}$. Improving pasteurization to preserve the biological components of donated human milk. Front Pediatr. 2018;6: 288. doi: https://doi.org/10.3389/fped.2018.00288.

44. Pitino MA, O 'Connor DL, Mcgeer AJ, Unger S. The impact of thermal pasteurization on viral load in human milk and other matrices : A rapid review. Appl Physiol Nutr Metab. 2020. doi: https://doi.org/10.1139/apnm-2020-0388.

45. Groß R, Conzelmann C, Müller JA, Stenger S, Steinhart $\mathrm{K}$, Kirchhoff F, et al. Detection of SARS-CoV-2 in human breastmilk. Lancet. 2020; 395(10239). doi: https://doi. org/10.1016/S0140-6736(20)31181-8.

46. Marinelli KA. Wet Nurses to Donor Milk Banks and Back Again: The Continuum of Sharing Our Milk to Save Lives. J Hum Lact. 2020;36(2):213-16. doi: https://doi. org/10.1177/0890334420927329.

47. Bar-Yam N. Important Milk Bank COVID-19 Update [Internet]. Mothers'Milk Bank Northeast;2020 [Fecha de consulta: 2 de junio de 2020]. Disponible en: https://milkbankne.org/2020/04/milk-bank-covid-19-update/.

48. Black RF. Transmission of HIV-1 in the breast feeding process. J Am Diet Assoc. 1996;96(3):267-74. doi: https://doi. org/10.1016/S0002-8223(96)00079-X.

49. Chen H, Guo J, Wang C, Luo F, Yu X, Zhang W, et al. Clinical characteristics and intrauterine vertical transmission potential of COVID-19 infection in nine pregnant women: a retrospective review of medical records. Lancet. 2020;395(10226):80915. doi: http://dx.doi.org/10.1016/S0140-6736(20)30360-3. 
50. Dunn DT, Newell ML, Ades AE, Peckham CS. Risk of human immunodeficiency virus type 1 transmission through breastfeeding. Lancet. 1992;340(8819):585-88.doi: https://doi. org/10.1016/0140-6736(92)92115-V.

51. Rabenau HF, Cinatl J, Morgenstern B, Bauer G, Preiser W, Doerr HW. Stability and inactivation of SARS coronavirus. Med Microbiol Immunol. 2005;194(1):1-6. doi: https://doi. org/10.1007/s00430-004-0219-0.

52. Dong L, Tian J, He S, Zhu C, Wang J, Liu C, et al. Possible Vertical Transmission of SARS-CoV-2 from an Infected Mother to Her Newborn. JAMA. 2020;323(18):1846-48. doi: https://doi.org/10.1001/jama.2020.4621.

53. Yan J, Guo J, Fan C, Juan J, Yu X, Li J, et al. Coronavirus disease 2019 in pregnant women: a report based on 116 cases. Am J Obstet Gynecol. 2020; 223(1): 111.e1-111.e14. doi: https:// doi.org/10.1016/j.ajog.2020.04.014.

54. Li Y, Nguyen DN, de Waard M, Christensen L, Zhou P, Jiang P, et al. Pasteurization Procedures for Donor Human Milk Affect Body Growth, Intestinal Structure, and Resistance against Bacterial Infections in Preterm Pigs.J Nutr. 2017;147(6):112130. doi: https://doi.org/10.3945/jn.116.244822.

55. Schlotterer HR, Perrin MT. Effects of Refrigerated and Frozen Storage on Holder-Pasteurized Donor Human Milk: A Systematic Review. Breastfeed Med. 2018;13(7):465-72.doi: https://doi.org/10.1089/bfm.2018.0135.

56. Escuder-Vieco D, Espinosa-Martos I, Rodríguez JM, Corzo N, Montilla A, Siegfried P, et al. High-temperature shorttime pasteurization system for donor milk in a human milk bank setting. Front Microbiol. 2018;9: 926. doi: https://doi. org/10.3389/fmicb.2018.00926.

57. Pitino MA, Unger S, Doyen A, Pouliot Y, Aufreiter S, Stone $\mathrm{D}$, et al. High hydrostatic pressure processing better preserves the nutrient and bioactive compound composition of human donor milk. J Nutr. 2019;149(3):497-504. doi: https://doi. org/10.1093/jn/nxy302.

58. Williams J, Namazova-Baranova L, Weber M, Vural M, Mestrovic J, Carrasco-Sanz A, et al. The importance of continuing breastfeeding during COVID-19: in support to the WHO statement on breastfeeding during the pandemic. J Pediatr. 2020; 223: 234-236. doi: https://doi.org/10.1016/j. jpeds.2020.05.009.

59. Pérez-Escamilla R, Cunningham K, Moran VH. COVID19 , food and nutrition insecurity and the wellbeing of children, pregnant and lactating women: A complex syndemic. Matern Child Nutr. 2020 Jul;16(3):e13036. doi: https:// doi. org/10.1111/mcn.13036.
60. Menendez C, Gonzalez R, Donnay F, Leke RGF. Avoiding indirect effects of COVID-19 on maternal and child health. Lancet Glob Health. 2020; 8(7): e863-e864. doi: http:// dx.doi.org/10.1016/S2214-109X(20)30239-4.

61. Fore HH. A wake-up call: COVID-19 and its impact on children's health and wellbeing. Lancet Glob Health. 2020;8(7):e861-e862. doi: http://dx.doi.org/10.1016/ S2214-109X(20)30238-2.

62. Moro GE, Billeaud C, Rachel B, Calvo J, Cavallarin L, Christen L, et al. Processing of donor human milk: Update and recommendations from the European Milk Bank Association (EMBA). Front Pediatr. 2019;7: 49. doi: http://dx.doi. org/10.3389/fped.2019.00049.

63. World Health Organization (WHO). COVID-19 and breastfeeding. Position paper. [Internet]: WHO, Regional office for Europe; 2020 [Fecha de consulta: 25 de mayo de 2020]. Disponible en: https://www.euro.who.int/_data/assets/ pdf_file/0010/437788/breastfeeding-COVID-19.pdf?ua=1.

64. PATH. Policy Brief: Ensuring equitable access to human milk for all infants A comprehensive approach to essential newborn care [Internet]. Seattle: PATH; 2017 [Fecha de consulta: 4 de abril 2020]. Disponible en: https://www.who.int/nutrition/ publications/infantfeeding/equitable-access-human-milkpolicybrief/en/.

65. UNICEF. UNICEF position regarding close contact and breastfeeding in COVID-19 context [Internet]. 2020 [Fecha de consulta: 10 de mayo de 2020]. Disponible en: https://www.unicef.org/romania/press-releases/unicefposition-regarding-close-contact-and-breastfeeding-covid-19-context\#: : text=In\%20the $\% 20$ context $\% 20$ of $\% 20$ COVID19,age\%20and\%20beyond)\%2C\%20but\%20they.

66. UNICEF. Breastfeeding safely during the COVID-19 pandemic [Internet]. May 28, 2020 [Fecha de consulta: 1 de junio de 2020]. Disponible en: https://www.unicef.org/coronavirus/breastfeeding-safely-during-covid-19-pandemic.

67. Marinelli KA, Lawrence RM. Safe Handling of Containers of Expressed Human Milk in all Settings During the SARSCoV-2 (COVID-19) Pandemic. J Hum Lact. 2020;00(0):1-4. doi: https://doi.org/10.1177/0890334420919083.

68. Stellwagen L, Chambers C. Response to: Safe Handling of Containers of Expressed Human Milk in all Settings During the SARS-CoV-2 (COVID-19) Pandemic (Marinelli and Lawrence, 2020). J Hum Lact. 2020;36(3):541. doi: https:// doi.org/10.1177/0890334420923364. 